\title{
Towards a Polymer-Brush-Based Friction Modifier for Oil
}

\author{
Tobias A. Gmür ${ }^{1}$. Joydeb Mandal ${ }^{1,2}$ - Juliette Cayer-Barrioz ${ }^{3}$ Nicholas D. Spencer ${ }^{1}$ (1)
}

Received: 2 June 2021 / Accepted: 11 August 2021 / Published online: 25 August 2021

(c) The Author(s) 2021, corrected publication 2021

\begin{abstract}
To meet the need for oil-compatible friction modifier additives that can significantly reduce energy consumption in the boundary-lubrication regime, a macromolecular design approach has been taken. The aim was to produce a lubricious polymer film on the sliding surfaces. A series of readily functionalizable block copolymers carrying an oleophilic poly(dodecyl methacrylate) block and a functionalizable poly(pentafluorophenyl methacrylate) block of various lengths was synthesized by means of reversible addition-fragmentation chain-transfer (RAFT) polymerization. The poly(pentafluorophenyl methacrylate) block was used to attach surface-active nitrocatechol anchoring groups to the polymer. The friction-reduction properties of these polymers were assessed with $0.5 \mathrm{wt} \%$ solutions in hexadecane by means of rolling-sliding macroscopic tribological tests. Block copolymers with roughly equal block lengths and moderate molecular weights were significantly more effective at friction reduction than all other architectures investigated. They also displayed lower friction coefficients than glycerol monooleate-a commercially used additive. The film-formation ability of these polymers was examined using a quartz-crystal microbalance with dissipation (QCM-D), by monitoring their adsorption onto an iron oxide-coated QCM crystal. The polymer with highest lubrication efficiency formed a thin film of $\sim 17 \mathrm{~nm}$ thickness on the crystal, indicating the formation of a polymer brush. Interferometric rolling-sliding experiments with the same polymer showed a separating film thickness of $\sim 20 \mathrm{~nm}$, which is consistent with the QCM-D value, bearing in mind the compression of the adsorbed layers on the two sliding surfaces during tribological testing.
\end{abstract}

\section{Graphical Abstract}
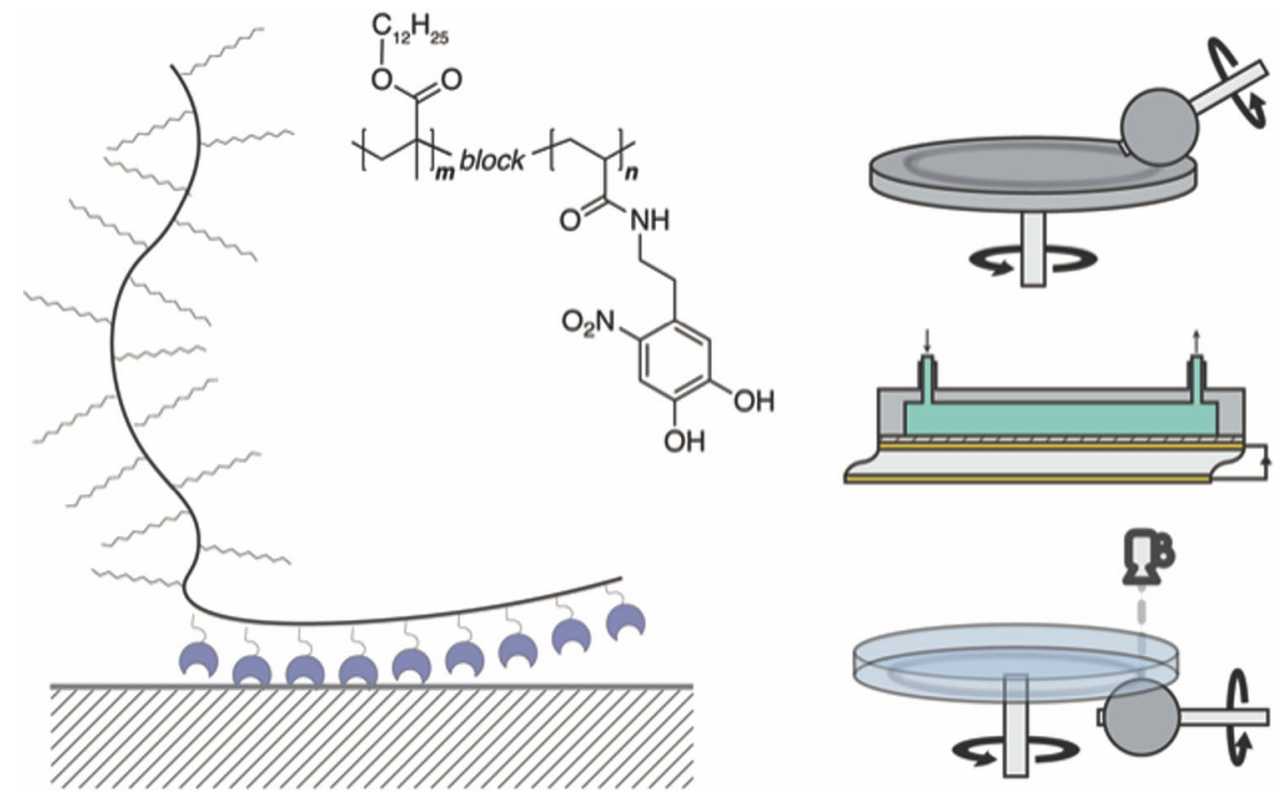

Keywords Lubricant additive $\cdot$ Friction reduction $\cdot$ RAFT polymerization $\cdot$ Block copolymer $\cdot$ Oil compatibility

Extended author information available on the last page of the article 


\section{Introduction}

We are living in a world in which both the sources and uses of energy are rapidly changing, with significant impact on our needs for lubricants, and especially for additives that are active in boundary lubrication. The advent of electric vehicles means that thermally activated lubricant additives are less effective, and it also presents new requirements for lubricants, such as extremely low viscosity at speeds higher than 20,000 rpm [1], placing greater demands on the boundary-lubrication performance upon startup. Internal combustion and hybrid vehicles will be with us for decades yet, and among the measures proposed for energy saving [2] have been self-healing ultrathin tribofilms that are active under boundary-lubrication conditions in reduced-viscosity lubricants [3]. Wind turbines have rapidly ascended in importance, but their effective lubrication, including under boundary-lubrication conditions, remains a significant challenge [4]. In short, the development of lubricant additives for the boundary regime, i.e. friction modifiers, is more important than ever.

New approaches are needed to improve upon the current state of the art in friction modifiers, which include small organic molecules, organo-molybdenum compounds, and, the focus of this study, polymeric additives [5]. Polymers have been found to be beneficial for friction and wear properties of engine oils for many decades [6]. In general, however, their use has been motivated by their viscositymodification [7] or dispersion [8] properties. The beneficial friction-reduction properties of polymeric friction modifiers (PFMs) in commercial engine oils were extensively investigated in the 1990s [9-11], and were ascribed [12] to a surface enrichment of the polymeric species, leading to a local increase in viscosity. Later investigations [13-16] reiterated the potential of PFMs, but the precise chemical identity of the investigated additives was generally undisclosed. A notable exception to this trend was the work from the group of Spikes at Imperial College, [17, 18], in which a broad range of poly(alkyl methacrylate)-based copolymers with a multitude of different polar groups, serving as surfaceactive moieties, were investigated. Polymer-architectural effects were highlighted by showing the superior frictionreduction properties of a block copolymer compared to a random copolymer.

The synthesis and friction/wear properties of novel viscosity modifiers have also been precisely described in recent years [19-21]. However, in general their effect on friction reduction under boundary-lubrication conditions is somewhat limited and requires relatively high polymer loadings.

The present study brings together two previous developments in polymer-brush lubrication. On the one hand oleophilic polymer brushes grown from a silicon surface were (a)

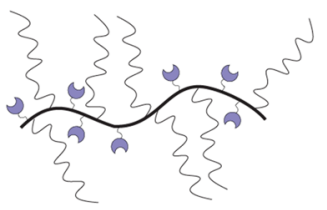

(c)

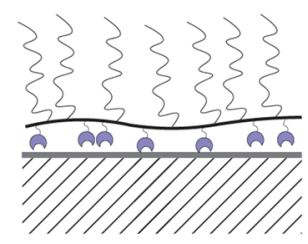

(b)

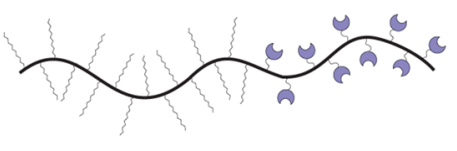

(d)

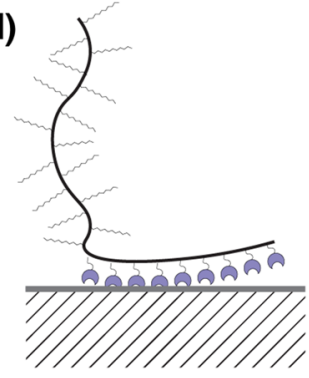

Fig. 1 Schematic depiction of the polymeric friction modifiers synthesized. a Graft copolymer and b block copolymer. c and d Hypothesized attachment configurations

shown to display excellent lubricious properties in a range of common base oils [22]. On the other hand, in aqueous environments it was found that a dilute solution of the graft copolymer poly(L-lysine)-graft-poly(ethylene glycol) (PLL$g$-PEG) could reduce friction dramatically, the $-\mathrm{NH}_{2}$ groups on the PLL backbone acting as anchors to the surface, and statistically grafted PEG chains forming a lubricious polymer brush [23]. In light of this, an initial study focused on the use of newly synthesized graft copolymers as schematically illustrated in Fig. 1a to reduce friction in oil, this time using oleophobic chains to form brushes and statistically distributed anchors that would form covalent bonds with the surface. The effectiveness of such an approach appeared to be very limited, however (see Sect. 1 in the Supporting Information for details). Previous investigations on graft copolymers such as PLL- $g$-PEG have shown experimentally [24] and through computational models [25], that in aqueous solutions the long-range electrostatic force is crucial for the graft copolymers to attach to the surface in a brush-like configuration, overcoming the steric hindrance of the polymer chains (e.g. the conformational transition from Fig. 1a to c). In oil, the surfaces are not intrinsically charged, and so this mechanism is not an option. The use of alternative anchoring strategies, such as the formation of covalent bonds, requires a closer approach of the anchor to the surface than is feasible in the presence of lengthy co-grafted polymer side chains.

One of the ways in which such a steric effect of the oleophilic side chains can be minimized is by designing block copolymers carrying an oil-soluble, brush-forming block and a surface-active block as depicted in Fig. 1b. This allows free access of the anchoring groups to the surface without impediment from the brush-forming chains. Clearly there 
(a)

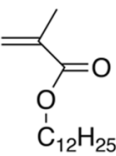<smiles>CCCCCCCCCCCC(C)(C)SC(=S)SC(C)(C)C#N</smiles>

(b)

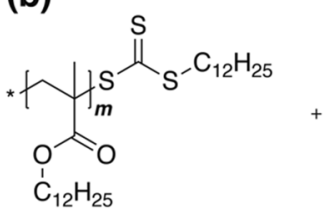<smiles>C=CC(=O)Oc1c(F)c(F)c(F)c(F)c1F</smiles>

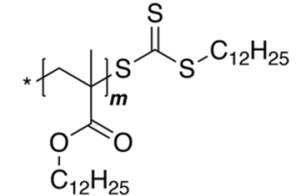

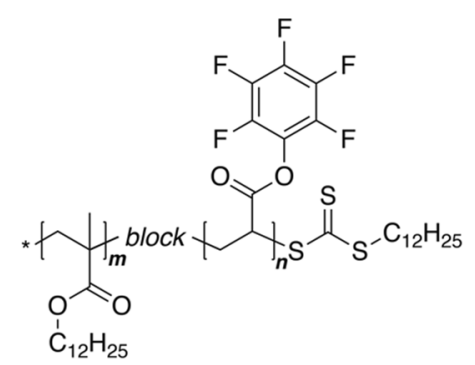

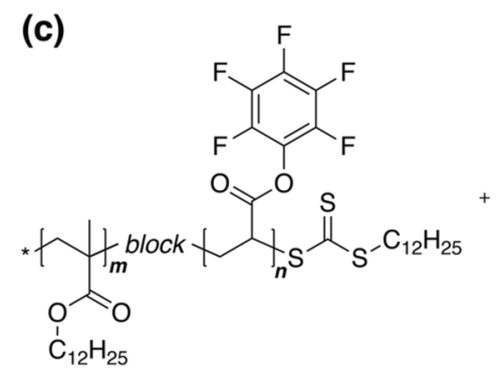<smiles>NCCc1cc(O)c(O)cc1[N+](=O)[O-]</smiles><smiles>CCCCCCCCCCCCCCCCCC(C)(C)C(=O)NCCc1cc(O)c(O)cc1[N+](=O)[O-]</smiles>

Fig. 2 Synthesis route of the p12MA-b-pNDAcrAm PFMs investigated. a Polymerization of the oleophilic block. b Functionalizable blockcopolymer synthesis. $\mathbf{c}$ Post-polymerization modification reaction

is a balance to be achieved between the length of the two kinds of blocks (i.e. polymer-architectural parameters), and there are many anchoring-group chemistries that could be explored. This paper describes the synthesis of novel block copolymer PFMs whose molecular structures have been designed to allow for facile exploration of both blockcopolymer architecture and anchoring chemistry. We focus here on the investigation of the architecture, the anchoring moieties being limited to nitrocatechol, which is designed to interact strongly and similarly with many non-noble, transition-metal surfaces (and the corresponding oxidized surfaces), such as steel, iron, or chromium, via a combination of coordination chemistry and hydrogen bonding [26-28], in contrast to the weaker, polar interactions that have been generally relied upon for PFMs to date. The influence of alternative anchoring chemistries will be reported in detail

Table 1 Detailed size descriptions of the investigated PFMs

\begin{tabular}{llllll}
\hline Name & PFM A & PFM B & PFM C & PFM D \\
\hline d.p. 12MA $m$ & 42 & 42 & 375 & 375 & 375 \\
d.p. NDAcrAm $n$ & 8 & 36 & 281 & 19 & 5 \\
Mn (kDa) & 13 & 20 & 162 & 100 & 97 \\
Functionalization (\%) & 10 & 41 & 37 & 4 \\
Schematic representation & & &
\end{tabular}

The degrees of polymerization (DP) are derived from NMR-based conversion measurements, as described in the Supporting Information. Average molecular weight $(\mathrm{Mn})$ and the ratio of 12MA to NDAcrAm units are derived from the DP directly 
elsewhere. The PFMs were evaluated for their frictional performance in rolling-sliding macroscale contact in low-viscosity oils, on both steel and chromium, and their adsorption properties were studied with the quartz-crystal microbalance (QCM) [29-37], using iron oxide-coated sensors.

\section{Materials and Methods}

\subsection{Materials}

The synthetic pathway is summarized in Fig. 2 (the details of raw materials used and synthesis conditions are given in Sect. 2 of the Supporting information). First, an oleophilic block is produced by RAFT polymerization of an oleophilic monomer to yield a polymer with an active chain end. This is used in a second polymerization as a macro chain-transfer agent (CTA). A block of functional units is added to the polymer, which is modified with nitrodopamine in a final step to yield a poly(dodecyl methacrylate)-block-poly(nitrodopamine acryl amide) (p12MA-b-pNDAcrAm).

Five different polymer structures are discussed here, with differing degrees of polymerization $\boldsymbol{m}$ and $\boldsymbol{n}$ (as derived from NMR conversion measurements) being presented in Table 1 . The motivation for the choice of synthesized structures was to start off at what is reported to work in the literature: block copolymers with an overall molecular weight of roughly $25 \mathrm{kDa}$ [37] and a functionalization percentage of $10 \mathrm{~mol} \%$ [18]. This was achieved with PFM A. The other structures were designed to investigate the effects of the different size parameters. While B contained a larger anchoring block, $\mathrm{D}$ and $\mathrm{E}$ were intended to take structure $\mathrm{A}$ to a higher molecular weight with constant relative and absolute anchoring block sizes, respectively. Polymer $\mathrm{C}$ is a larger version of $\mathrm{B}$ and was synthesized in light of the promising early results of the latter.

The additives were dissolved at $0.5 \mathrm{wt} \%$ in either hexadecane (Acros Organics), PAO2 or PAO6 (both kindly donated by Blaser Swisslube) at $80{ }^{\circ} \mathrm{C}$ under stirring overnight. All solutions were subsequently left to reach room temperature, centrifuged at $4000 \mathrm{rpm}$ for $10 \mathrm{~min}$, decanted and only the supernatant liquid used for further experiments.

\section{Methods}

\subsection{Rheometry}

Rheological measurements in an Anton Paar MCR302 Rheometer with double-wall accessory were used to quantify the effect of PFM-additive addition to the bulk dynamic viscosity of hexadecane. For PAO2 and PAO6, the measurements were carried out in a cone/plane rheometer with a $60 \mathrm{~mm}$ diameter cone and a shear rate of $10 \mathrm{~s}^{-1}$ and $0.1 \mathrm{~s}^{-1}$, respectively, covering the range $15-60{ }^{\circ} \mathrm{C}$.

\subsection{QCM-D}

Quartz-crystal-microbalance measurements were conducted on a QCM-D E4 (Biolin Scientific AB, Sweden) at $25^{\circ} \mathrm{C}$. To obtain reproducible results, the iron oxide (QSX 326, $\mathrm{Fe}_{3} \mathrm{O}_{4}$ ) coated sensors were only used freshly out of the box. They were sonicated for $20 \mathrm{~min}$ in ethanol, rinsed with ultrapure water and blown dry with filtered nitrogen. The rest of the measurement setup was sonicated in isopropanol and hexane prior to assembly. Each of the four cells was connected in parallel to a peristaltic pump and rinsed with hexadecane for $4 \mathrm{~h}$ at a constant flow rate of $2.5 \mu \mathrm{L} / \mathrm{s}$ through each sensor to achieve a flat baseline. The subsequent measurement consisted of $20 \mathrm{~min}$ of further equilibration, after which the lubricant solution was flowed through the cells for $20 \mathrm{~min}$, and finally the cells were purged with pure hexadecane again for $20 \mathrm{~min}$.

The adsorbed masses of the polymers (including trapped solvent) were calculated using the Sauerbrey equation [38]. Measurements were carried out using four sensors simultaneously, although only for overtones 5, 7, and 9 was the signal-to-noise ratio deemed sufficient for further processing. The presented derived quantities are the averages of those 12 different values with standard deviations.

\subsection{Tribology: MTM}

The mini-traction-machine (MTM) measurements were performed on a MTM2 (PCS Instruments, UK) with the standard specimen pack (100Cr6 balls and disks, $R_{\mathrm{a}}<20 \mathrm{~nm}$ ) as received and sonicated in isooctane. The temperature was set to $30{ }^{\circ} \mathrm{C}$ and the normal load maintained at $2 \mathrm{~N}$ if not mentioned otherwise, resulting in an average pressure of $256 \mathrm{MPa}$. Stribeck curves were obtained repeatedly with increasing and decreasing speed ramps from 1 to $2000 \mathrm{~mm} / \mathrm{s}$. The slide-to-roll ratio, as defined by $\mathrm{SRR}=$ $U_{\text {sliding }} / U_{\text {entrainment }}=2 *\left|U_{\mathrm{b}}-U_{\mathrm{d}}\right| /\left(U_{\mathrm{b}}+U_{\mathrm{d}}\right)$ was maintained at $50 \%$ throughout, where $\mathrm{U}_{\mathrm{b}}$ and $\mathrm{U}_{\mathrm{d}}$ correspond to speeds of the ball and disk, respectively, with respect to the contact. Running-in effects made the first measurement incomparable to the rest of the set, which is why it was omitted. The data presented for the Stribeck-curve measurements are averages, together with their $95 \%$ confidence intervals from 4 repetitions. Comparative measurements were performed in pure hexadecane and with 0.5.wt\% glycerol monooleate (GMO), which is a commercially used organic friction modifier. 


\subsection{Tribology: IRIS}

The IRIS tribometer, developed in LTDS, Ecole centrale de Lyon, is described in detail elsewhere [39]. In short, a 100Cr6 steel ball and a silica disk (sonicated in heptane and isopropanol, and then dried under nitrogen flow) are brought into contact and rotated independently under controlled kinematic conditions. The polished ball and the disk both had a rms roughness of $5 \mathrm{~nm}$, measured with a Bruker Contour GT-K interferometer. The silica disk was coated with a 6-nm thick semi-transparent chromium layer that allowed for visualization of the tribocontact and simultaneous interferometric determination of the absolute distance between the two. The normal force was fixed at $5 \mathrm{~N}$ (resulting in an average pressure of $212 \mathrm{MPa}$ ) and continually monitored on the ball, while the torque on the disk assembly allowed for the direct calculation of friction forces. These conditions (metallic surfaces and contact pressures) were selected, in order to monitor film formation under similar conditions as in the MTM experiments. The actual measurement started with an initial pure rolling period at $10 \mathrm{~mm} / \mathrm{s}$. After this, the SRR was set to $50 \%$ and the entrainment velocity was decreased to $2 \mathrm{~mm} / \mathrm{s}$, increased to $200 \mathrm{~mm} / \mathrm{s}$ and decreased to $10 \mathrm{~mm} / \mathrm{s}$ again stepwise. The first pure rolling step was used to calculate the frictional force offset, later pure rolling steps served as a measure to check for instrumental drift. The traction coefficient reported at any given entrainment velocity is the average between positive and negative SRR ratios (i.e. only Couette friction is considered and the Poiseuille term is neglected), while the error bars represent the aggregated $95 \%$ confidence interval. The measurements were conducted under ambient conditions (i.e. $27.5^{\circ} \mathrm{C}$ and $40 \mathrm{RH} \%$ ).

The film thickness and its distribution in the high-pressure zone were measured using two independent methods: in situ during the experiment, using the color of the steel/chromium contact with an appropriate calibration, and post-experiment, using a spacer-layer-coated disk. The first method gave a comparative, order-of-magnitude estimate of the evolution of the film thickness with the entrainment velocity, averaged over 6 images with low resolution (about $10 \mathrm{~nm}$ ) while the second method gave a more accurate and absolute value of the adsorbed film thickness on the steel ball after the experiment with a resolution of a few nanometers.

In parallel, these experimental values were compared to the calculated hexadecane film thickness. The pressure-viscosity coefficient of hexadecane was deduced from the data presented by Meng et al.[40] fitted with Roelands' equation[41] and a viscosity of $3 \mathrm{mPa}$.s. The resultant value, $\alpha=10 \mathrm{GPa}^{-1}$, was low, leading to the use of Moes-Venner prediction[42] to calculate the hexadecane film thickness.

\section{Results and Discussion}

\subsection{Effect of Additives on Viscosity}

The addition of very small amounts of polymer to hexadecane did not have a significant influence on the measured viscosity as presented in Table 2 . In fact, the maximum viscosity increase was $<10 \%$. This was to be expected, since the concentration is also at the lower end of the range reported for previous PFM investigations.

\subsection{Friction Behavior (MTM)}

The efficacy of the developed PFMs was examined in MTM experiments by measuring their friction behavior and plotting the coefficient of traction (COT) against entrainment speed. A comparison of all synthesized PFMs as well as results for pure hexadecane and the GMO solution is shown in Fig. 3a. When the entrainment speed is higher than $1000 \mathrm{mms}^{-1}$, all the measurements overlap at very low friction values, corresponding to the onset of hydrodynamic lubrication. The results for the decreasing speed ramps are omitted for clarity, since no indication of hysteresis was observed.

In the mixed/boundary regime the results fall into three categories: (a) Pure hexadecane shows extremely high friction, reaching 0.3 with a large scatter, (b) most of the polymers appear to be as effective as GMO, with a maximum friction coefficient of about 0.17 , and (c) PFM-B, which exhibits an exceptionally low friction coefficient $(\sim 0.06)$ throughout the measured speed range of 1 to $100 \mathrm{~mm} \mathrm{~s}^{-1}$, resembling the previously observed friction behavior for "covalently grafted" poly(dodecyl methacrylate) brushes in oil [22].

To gain a better understanding of the efficacy of PFM B, similar MTM experiments were performed in different base oils: hexadecane, PAO2 and PAO6. The results are plotted in Fig. 3b, where the viscosity of the base oil was factored into the $\mathrm{X}$-axis. PFM-B consistently shows greater friction reduction, especially in the boundary regime, compared to GMO. Hardly any influence of the base oil viscosity was detected in the boundary regime, confirming that a surface effect was

Table 2 Measured kinetic viscosity in a $0.5 \mathrm{wt} \%$ solution in hexadecane

\begin{tabular}{llllllll}
\hline Additive & PFM A & PFM B & PFM C & PFM D & PFM E & GMO & w/o \\
\hline $\begin{array}{c}\text { Dynamic viscosity } \\
\text { (mPa s) }\end{array}$ & $2.993 \pm 0.013$ & $3.029 \pm 0.011$ & $3.025 \pm 0.017$ & $3.241 \pm 0.013$ & $3.063 \pm 0.016$ & $2.947 \pm 0.014$ & $2.951 \pm 0.016$ \\
\hline
\end{tabular}



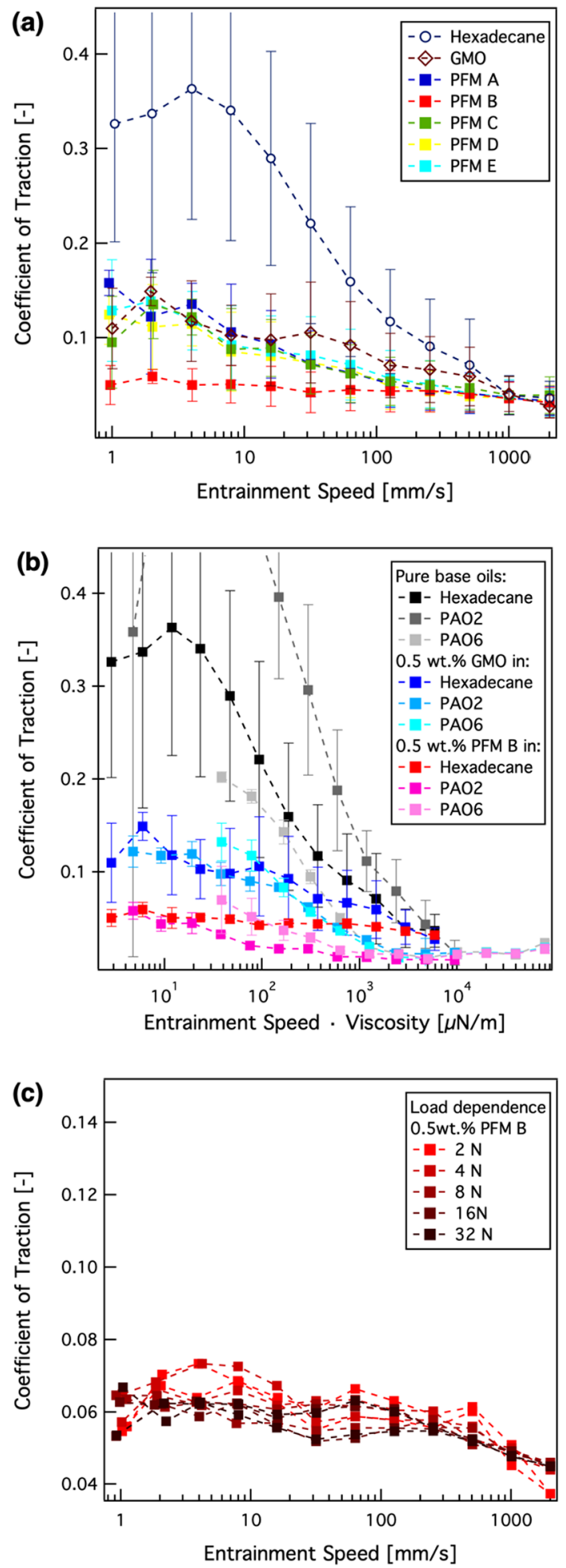

Fig. 3 a MTM results for the investigated PFMs. b Performance assessment of PFM B in different base oils at $30^{\circ} \mathrm{C}$. c Load-dependent measurements with $0.5 \mathrm{wt} \%$ PFM B in hexadecane being measured. Finally, the low-friction behavior of PFM B can be further examined by examining Stribeck curves that were obtained upon increasing normal load, as shown in Fig. 3c. No significant differences are seen here, even though the maximum contact pressure reaches $960 \mathrm{MPa}$.

\subsection{Existence of an Adsorbed Film Under Unperturbed Conditions (QCM-D)}

Film formation by PFM B was examined using the quartzcrystal microbalance with dissipation (QCM-D). In Fig. 4 a set of exemplary raw-data graphs is depicted. The measurements are separated into three phases: the first approximately 25 min consists of a constant flow of hexadecane, to obtain a baseline, after which the lubricant solutions are added and reach the sensor cells. After an additional roughly $20 \mathrm{~min}$, the cells are purged with pure hexadecane for an additional $20 \mathrm{~min}$. Only the central three frequencies are shown and later analyzed, since the higher- and lower-order overtones displayed a poor signal-to-noise ratio. The raw-data graph for PFM E is barely distinguishable from that of PFM D shown in Fig. 4d, and can be found in the Supporting Information.

In Fig. $4 \mathrm{e}$-depicting the reference friction modifier GMO - a constant instrumental drift for the $\Delta \mathrm{F}_{\mathrm{n}} / \mathrm{n}$ signal is clearly visible. This is observed in all measurements (with slightly different magnitudes and prefixes), but is best visible here because of the lower scale of the y-axis. Keeping this in mind one sees that the frequency-shift and dissipation signals do return to pre-adsorption values after rinsing, which indicates a dynamic equilibrium and thus complete detachment of the film upon rinsing. All polymer-containing lubricant formulations, on the other hand, show a residual change in $\Delta \mathrm{F}_{\mathrm{n}} / \mathrm{n}$, i.e. the film is bound strongly enough to be irreversibly adsorbed.

For PFM A, significant mass is adsorbed irreversibly, i.e. remains upon rinsing. The decrease in dissipation upon rinsing indicates, however, that a rearrangement of the film occurred. PFM B has a visibly faster adsorption rate than the other polymers, and the thick film resulting after a few minutes shows little sign of rearrangement upon rinsing. Figure $4 \mathrm{c}$ highlights the extremely slow adsorption kinetics of PFM C, which can be attributed to its high molecular weight. No decrease in dissipation again indicates no film rearrangement. PFM D (as well as E shown in Figure S15) resembles PFM A in its trends, but the absolute values for frequency and dissipation shifts are approximately a factor of 2 higher. Finally, a reference measurement with the oleophilic chain only (the precursor molecule to PFMs A and B) shown in Fig. $4 \mathrm{f}$ provides additional insight. There is significant, but slow adsorption, and the adsorbed films show rearrangement upon rinsing. This can be rationalized by the fact that the methacrylate unit of the p12MA chain is inherently polar, and therefore there will be a tendency for the molecule to 

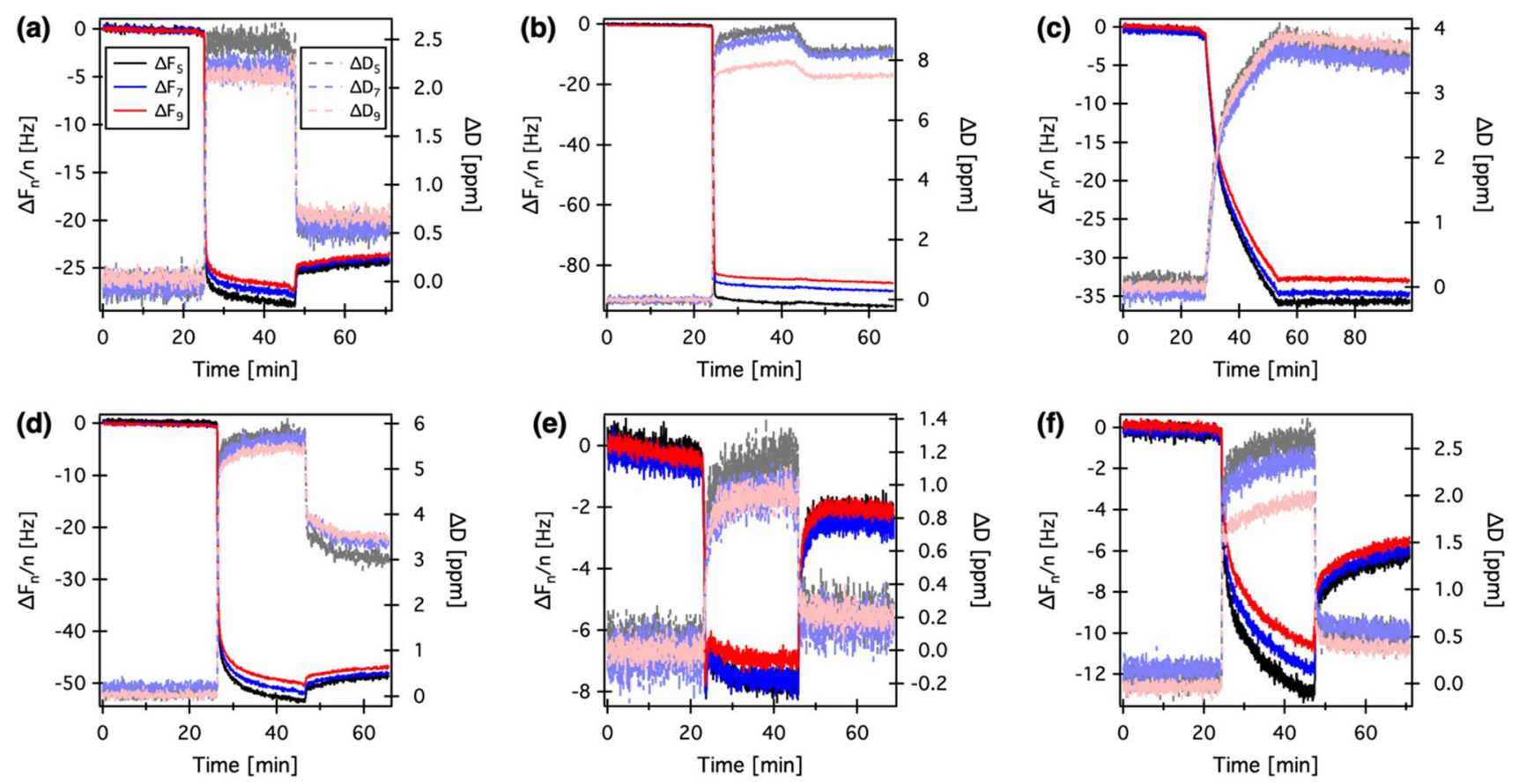

Fig. 4 Raw data from QCM-D measurements (a-d) PFMs A to D, respectively, e GMO, f p12MA

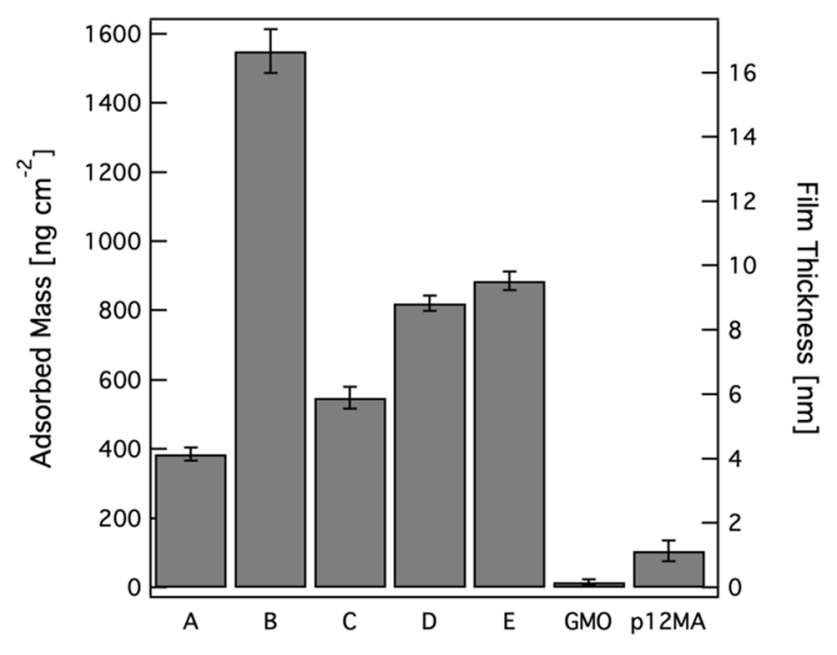

Fig. 5 Irreversibly adsorbed masses and approximated thicknesses derived from QCM measurements

adsorb to the oxide surface when the alternative is the very non-polar hexadecane. The overall polarity of the molecule is also an explanation for the different behavior of PFMs B and $\mathrm{C}$ compared to the others: the percentage of functional, polar groups is, at $>30 \%$, very high.

The irreversible-mass-adsorption results are quantified in Fig. 5. As expected from the tribological results, the lubricant containing PFM B exhibits significantly different behavior compared to the others. The irreversibly adsorbed masses (i.e. after rinsing) are shown on the left axis, with the Sauerbrey assumption of a rigid, laterally homogeneous film (see also Supporting Information).

The conversion into film thickness shown on the right axis assumes a density of $0.93 \mathrm{~g} \mathrm{~cm}^{-3}$ (p12MA in bulk) for the polymer and incorporated solvent. For PFM B in hexadecane, the resulting thickness is $16.4 \pm 0.7 \mathrm{~nm}$, the highest of all samples measured. Assuming an all-trans zigzag conformation of the backbone chain, one would expect between $10.5 \mathrm{~nm}$ (for the oleophilic block only) and $19.5 \mathrm{~nm}$ for the entire polymer.

Despite having the highest molecular weight and a high degree of anchor functionalization, PFM C adsorbs to a lesser extent than three of the other block copolymers. This is likely due to its large molecular size, which leads to a blocking of potential surface adsorption sites. GMO in hexadecane shows an equilibrium thickness of $1.3 \mathrm{~nm}$ (but a negligible irreversibly adsorbed amount), which corresponds to what has been reported using other techniques [43], supporting the validity of our experimental conditions and modeling used for the determination of film thickness.

These estimated thicknesses here are mainly for comparison, and are to be considered as approximations, especially since the Sauerbrey equation assumes only a solid adsorbed slab of material. The layer whose thickness we are measuring also incorporates an unknown amount of hexadecane as solvent, some of which may be partially protruding from the polymer layer. Finally, the polydispersity of the polymer means that a fraction of longer chains is protruding from the surface, leading to an overestimation of the adsorbed 

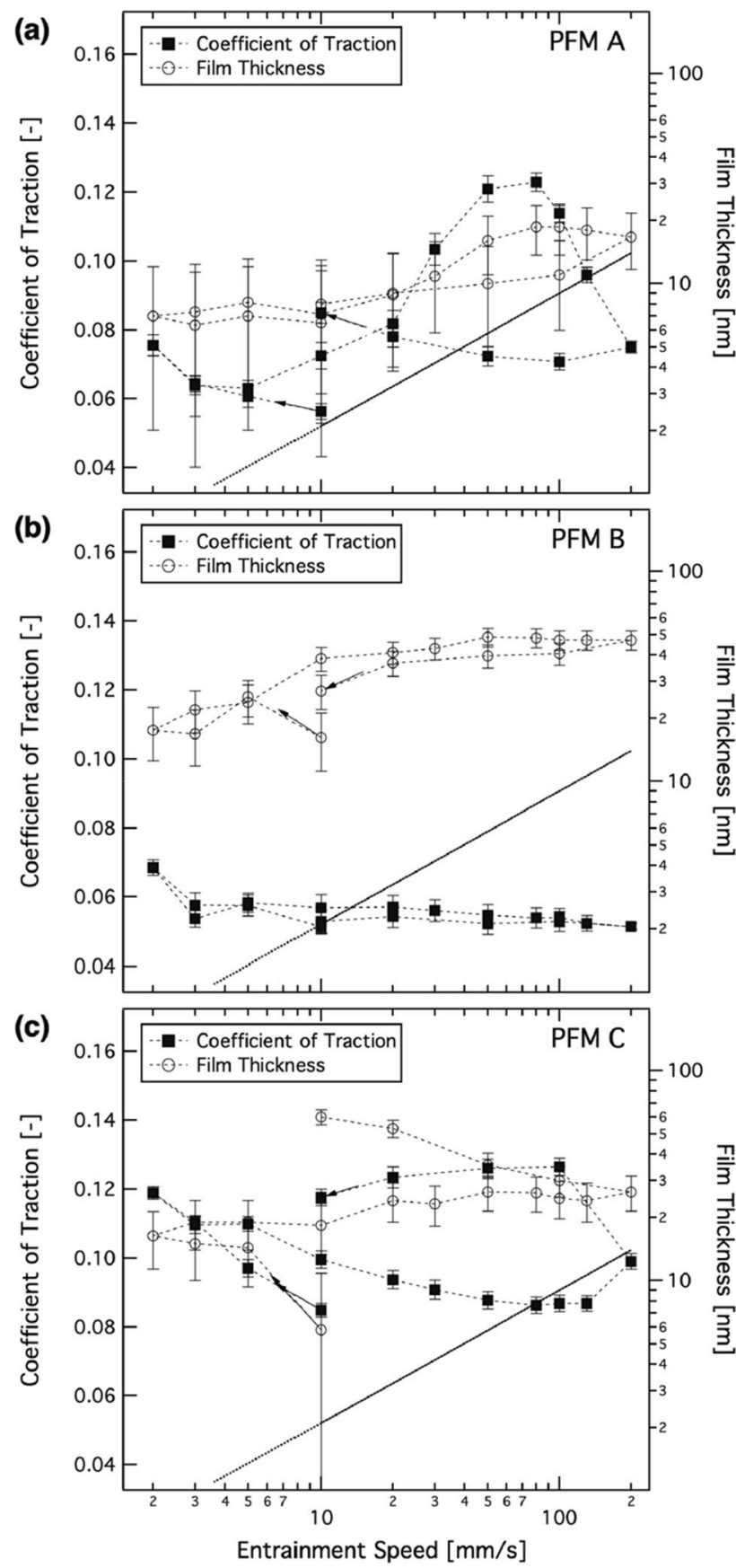

Fig. 6 IRIS measurement results. The first and last measurement steps are indicated with arrows, and the dotted lines indicate the chronological evolution. a-c PFM A-C, respectively. The straight dotted line is the expected hydrodynamic film thickness of pure hexadecane (Moes-Venner [41])

mass. In view of these caveats, it is likely that we are overestimating the thickness of the polymer layer for PFM B. Nevertheless we are within a thickness range consistent with the p12MA chains being upright in a brush-like configuration, the space between them being filled with solvent (hexadecane) molecules. Potentially, some of the adjacent anchoring groups are also constituting part of the brushforming chains.

The deduced thicknesses for all other PFMs are much lower, indicating unoriented, "mushroom" monolayer adsorption and neither brush nor multilayer formation. Additional ex situ ellipsometry measurements of the additives adsorbed on $\mathrm{Cr}$ surfaces from hexadecane yielded drythickness values corresponding to a packing density of $\approx 0.2$ chains.nm ${ }^{-2}$ for PFMs A and B, which would be consistent with the formation of a polymer brush (see Supporting Information).

\subsection{Correlation Between the Presence of an Adsorbed Film and Low Friction (IRIS)}

In order to confirm the role of the adsorbed film on the low friction behavior in the mixed/boundary lubrication regimes, solutions of PFMs A, B and C in hexadecane were investigated with IRIS. The results of the measurements, in which film thickness and friction coefficient are measured simultaneously, are summarized in Fig. 6.

For all polymers, the film thickness was large compared to that calculated for hexadecane, especially at low entrainment velocity, indicating that hydrodynamic effects alone could not explain the film-formation mechanisms. Contact visualization, during and after friction experiments, showed that a boundary film was adsorbed on the surfaces. This was also confirmed by the shape of the meniscus in the outlet zone at low entrainment velocity, a signature of a modification of surface properties. The thickness and heterogeneity of the adsorbed film and its capacity to withstand shear were dependent on the polymer architecture (see Figures S19, S20 and $\mathrm{S} 21$ ).

The friction measurement for PFM A shows significant hysteresis for entrainment velocities larger than $20 \mathrm{~mm} / \mathrm{s}$. This hysteresis was concomitant with that seen in the film evolution. The point of highest measured friction coincides with a visible onset of wear of the chromium coating of the disk (see also Figure S19). The measured film thickness is only approaching the regime expected for hexadecane at high entrainment speeds. In the lower-speed range, however, a speed-independent film in the range of $7 \mathrm{~nm}$ was visible, which again was consistent with both the post-friction adsorbed film measurement and the QCM results.

PFM B shows the lowest friction coefficient, consistent with the MTM measurements, despite the different surface roughness and substrate chemistry in the IRIS measurements. Negligible hysteresis was observed in friction and film thickness, highlighting the robustness of the adsorbed polymer film. The low friction coincided with the presence of a measured adsorbed film in the range of $20 \mathrm{~nm}$. This corresponds reasonably well with that measured in QCM, keeping in mind that we expect an adsorbed film on each surface 
that is under significant compression $\left(P_{\mathrm{av}}=212 \mathrm{MPa}\right)$. The film distribution was homogeneous, uniformly covering the surface, regardless of the entrainment velocity, confirming the strong anchoring of the polymers on metallic surfaces and the absence of contact bridging.

PFM C exhibited a continuous increase in measured film thickness during the IRIS experiment. At the end of the measurements, the film was patchy and thickness increased to $100 \mathrm{~nm}$ (Figure S21) compared to the thickness of $6 \mathrm{~nm}$ measured at the beginning of the experiment. The initially measured $6 \mathrm{~nm}$ thickness was consistent with the thickness derived from QCM-D experiments, while the $100 \mathrm{~nm}$ thickness measured at the end of the IRIS measurement is comparable with the large PFM C molecule in a brush configuration. This increase in film thickness was not observed during the initial pure rolling step at constant velocity, indicating that shear in the contact might be favoring the formation of the adsorbed film. A possible interpretation is that the shearing at the inlet zone of the contact and/or in the high-pressure contact zone allows for re-arrangements of the polymer molecules and a densification of the formed film. The formation of multilayers of polymer aggregates could also be a reason of the thick adsorbed film. The friction trends show a hysteresis, where the largest difference between decreasing and increasing speed is at $100 \mathrm{~mm} / \mathrm{s}$ the same speed at which the film-thickness measurements start to show large deviations. The absolute friction values in the final measurement stages are in a similar range to those measured with MTM. This seems to confirm the existence of a run-in phase in the film formation/friction evolution.

\section{Conclusions}

A series of polymeric friction modifiers (PFM) was synthesized with a range of precisely chosen structures and a specific chemistry. The chosen synthesis route allowed for the decoupling of effects due to polymer structure and anchoring chemistry (the latter being the topic of a subsequent study). Additionally, it opened the route for novel anchoring concepts to be explored in the field of oil-based polymeric friction modifiers.

A combination of a structure with an unusually large nitrodopamine anchoring block and moderate molecular weight (PFM B) showed unparalleled friction-reduction performance in rolling-sliding measurements, while other structures (some resembling the architecture of the published state-of-the-art, PFM A) showed a smaller effectcomparable to that of a reference organic friction modifier, glycerol monooleate.

In QCM-D measurements, all polymers adsorbed irreversibly onto the iron oxide surfaces, while glycerol monooleate was shown to adsorb reversibly. The film formed from the best-performing PFM (B) showed the highest adsorbed mass. The derived thickness of approximately $17 \mathrm{~nm}$ is comparable to the polymer size, implying a brush-like structure, firmly anchored to the surface by a substantial portion of the block of nitrodopamine groups.

IRIS measurements indicate various reasons for the less effective friction-reduction behavior of some of the PFMs. For PFM B, a uniformly adsorbed film was measured that was of comparable thickness to that measured by QCM-D, and it was stable under the applied contact pressure and shear conditions, resulting in a drastic friction reduction in the boundary regime.

Thus, it appears that the use of a block of nitrodopamine anchors is a very promising approach to anchoring blocks of brush-forming chains on ferrous surfaces in oil, and that the architecture of the polymer plays an important role in its effectiveness as a boundary lubricant. Overall molecular weight and relative sizes of anchoring and brush-forming blocks appear to be crucial parameters.

Supplementary Information The online version contains supplementary material available at https://doi.org/10.1007/s11249-021-01496-w.

Authors' Contributions All authors involved at all stages.

Funding Open Access funding provided by ETH Zurich. N/A.

\section{Declarations}

Conflict of interest Patent filed on similar topic.

Open Access This article is licensed under a Creative Commons Attribution 4.0 International License, which permits use, sharing, adaptation, distribution and reproduction in any medium or format, as long as you give appropriate credit to the original author(s) and the source, provide a link to the Creative Commons licence, and indicate if changes were made. The images or other third party material in this article are included in the article's Creative Commons licence, unless indicated otherwise in a credit line to the material. If material is not included in the article's Creative Commons licence and your intended use is not permitted by statutory regulation or exceeds the permitted use, you will need to obtain permission directly from the copyright holder. To view a copy of this licence, visit http://creativecommons.org/licenses/by/4.0/.

\section{References}

1. Farfan-Cabrera, L.I.: Tribology of electric vehicles: A review of critical components, current state and future improvement trends. Tribol. Int. 138, 473-486 (2019)

2. Carpick, R.W., Jackson, A., Lee, P., Argibay, N., Pachon Garcia, A., Sawyer, G., Bennett, K.: Tribology Opportunities or Enhancing America's Energy Efficiency. (2017)

3. Ishizaki, K., Nakano, M.: Reduction of $\mathrm{CO}_{2}$ emissions and cost analysis of ultra-low viscosity engine oil. Lubricants. 6, 102 (2018). https://doi.org/10.3390/lubricants6040102 
4. Dhanola, A., Garg, H.C.: Tribological challenges and advancements in wind turbine bearings: a review. Eng. Failure Anal. 118, 104885 (2020)

5. Spikes, H.: Friction Modifier Additives. Tribol. Lett. 60, (2015). https://doi.org/10.1007/s11249-015-0589-z

6. Okrent, E.H.: The effect of lubricant viscosity and composition on engine friction and bearing wear. ASLE Trans. 4, 97-108 (1961). https://doi.org/10.1080/05698196108972423

7. Martini, A., Ramasamy, U.S., Len, M.: Review of viscosity modifier lubricant additives. Tribol. Lett. 66, 1-14 (2018). https://doi. org/10.1007/s11249-018-1007-0

8. Burrington, J.D., Pudelski, J.K., Roski, J.P.: Challenges in Detergents and Dispersants for Engine Oils. In: Practical Advances in Petroleum Processing. pp. 579-595. Springer, New York (2007)

9. Cann, P.M., Spikes, H.A.: The behavior of polymer solutions in concentrated contacts: immobile surface layer formation. Tribol. Trans. 37, 580-586 (1994). https://doi.org/10.1080/1040200940 8983332

10. Smeeth, M., Spikes, H.A., Gunsel, S.: The formation of viscous surface films by polymer solutions: boundary or elastohydrodynamic lubrication? Tribol. Trans. 39, 720-725 (1996). https://doi. org/10.1080/10402009608983589

11. Gunsel, S., Smeeth, M., Spikes, H.: Friction and wear reduction by boundary film-forming viscosity index improvers. SAE Tech. Pap. (1996). https://doi.org/10.4271/962037

12 Guangteng, G., Smeeth, M., Cann, P.M., Spikes, H.A.: Measurement and modelling of boundary film properties of polymeric lubricant additives. Proc. Inst. Mech. Eng. Part J 210, 1-15 (1996). https://doi.org/10.1243/PIME_PROC_1996_210_473_02

13. Tohyama, M., Ohmori, T., Murase, A., Masuko, M.: Friction reducing effect of multiply adsorptive organic polymer. Tribol. Int. 42, 926-933 (2009). https://doi.org/10.1016/j.triboint.2008. 12.012

14. Aoki, S., Yamada, Y., Fukada, D., Suzuki, A., Masuko, M.: Verification of the advantages in friction-reducing performance of organic polymers having multiple adsorption sites. Tribol. Int. 59, 57-66 (2013). https://doi.org/10.1016/j.triboint.2012.06.001

15. Hobday, I., Eastwood, J.: Friction modifiers for next generation engine oils. Lube Mag. 92. (2014). https://doi.org/10.21203/rs.3. rs-587082/v1

16. Guegan, J., Southby, M., Spikes, H.: Friction modifier additives, synergies and antagonisms. Tribol. Lett. 67, 1-12 (2019). https:// doi.org/10.1007/s11249-019-1198-z

17. Müller, M., Topolovec-Miklozic, K., Dardin, A., Spikes, H.A.: The design of boundary film-forming pma viscosity modifiers. Tribol. Trans. 49, 225-232 (2006). https://doi.org/10.1080/05698 190600614833

18. Fan, J., Müller, M., Stöhr, T., Spikes, H.A.: Reduction of friction by functionalised viscosity index improvers. Tribol. Lett. 28, 287-298 (2007). https://doi.org/10.1007/s11249-007-9272-3

19. Cosimbescu, L., Vellore, A., Ramasamy, U.S., Burgess, S.A., Martini, A.: Low molecular weight polymethacrylates as multifunctional lubricant additives. Eur. Polym. J. 104, 39-44 (2018). https://doi.org/10.1016/j.eurpolymj.2018.04.029

20. Bapat, A.P., Erck, R., Seymour, B.T., Zhao, B., Cosimbescu, L.: Lipophilic polymethacrylate ionic liquids as lubricant additives. Eur. Polym. J. 108, 38-47 (2018). https://doi.org/10.1016/j.eurpo lymj.2018.08.026

21. Campbell, K.B., Erck, R., Swita, M., Cosimbescu, L.: Multifunctional tunable polymethacrylates for enhanced shear stability and wear prevention. ACS Appl. Polym. Mater. (2020). https://doi.org/ 10.1021/acsapm.0c00389

22. Bielecki, R.M., Crobu, M., Spencer, N.D.: Polymer-brush lubrication in oil: sliding beyond the stribeck curve. Tribol. Lett. 49, 263-272 (2013). https://doi.org/10.1007/s11249-012-0059-9
23. Lee, S., Müller, M., Heeb, R., Zürcher, S., Tosatti, S., Heinrich, M., Amstad, F., Pechmann, S., Spencer, N.D.: Self-healing behavior of a polyelectrolyte-based lubricant additive for aqueous lubrication of oxide materials. Tribol. Lett. 24, 217-223 (2006). https://doi.org/10.1007/s11249-006-9121-9

24. Serrano, Â.: Novel Polymer-Brush Based Coatings for Regulating Bioadhesion, PhD Thesis, ETH Zürich (2014) https://doi.org/10. 3929/ethz-a-010295870

25. Feuz, L.: On the conformation of graft-copolymers with polyelectrolyte backbone in solution and adsorbed on surfaces, $\mathrm{PhD}$ Thesis, ETH Zürich, (2006) https://doi.org/10.3929/ethz-a-01002 5751

26. Zürcher, S., Wäckerlin, D., Bethuel, Y., Malisova, B., Textor, M., Tosatti, S., Gademann, K.: Biomimetic surface modifications based on the cyanobacterial iron chelator anachelin. J. Am. Chem. Soc. 128, 1064-1065 (2006). https://doi.org/10.1021/ja056256s

27. Amstad, E., Gillich, T., Bilecka, I., Textor, M., Reimhult, E.: Ultrastable iron oxide nanoparticle colloidal suspensions using dispersants with catechol-derived anchor groups. Nano Lett. 9, 4042-4048 (2009). https://doi.org/10.1021/nl902212q

28. Saiz-Poseu, J., Mancebo-Aracil, J., Nador, F., Busqué, F., RuizMolina, D.: The chemistry behind catechol-based adhesion. Angew. Chem. Int. Ed. 58, 696-714 (2019)

29. Reviakine, I., Johannsmann, D., Richter, R.P.: Hearing what you cannot see and visualizing what you hear: interpreting quartz crystal microbalance data from solvated interfaces. Anal. Chem. 83, 8838-8848 (2011). https://doi.org/10.1021/ac201778h

30. Lundgren, S.M., Persson, K., Kronberg, B.T., Claesson, P.M.: Adsorption of fatty acids from alkane solution studied with quartz crystal microbalance. Tribol. Lett. 22, 15-20 (2006). https://doi. org/10.1007/s11249-005-9000-9

31. Lundgren, S.M., Persson, K., Mueller, G., Kronberg, B., Clarke, J., Chtaib, M., Claesson, P.M.: Unsaturated fatty acids in alkane solution: adsorption to steel surfaces. Langmuir 23, 10598-10602 (2007). https://doi.org/10.1021/la700909v

32. Nalam, P.C., Pham, A., Castillo, R.V., Espinosa-Marzal, R.M.: Adsorption behavior and nanotribology of amine-based friction modifiers on steel surfaces. J. Phys. Chem. C 123, 13672-13680 (2019). https://doi.org/10.1021/acs.jpcc.9b02097

33 Zachariah, Z., Nalam, P.C., Ravindra, A., Raju, A., Mohanlal, A., Wang, K., Castillo, R.V., Espinosa-Marzal, R.M.: Correlation between the adsorption and the nanotribological performance of fatty acid-based organic friction modifiers on stainless steel. Tribol. Lett. 68, 100 (2020). https://doi.org/10.1007/ s11249-019-1250-z

34. Fry, B.M., Moody, G., Spikes, H.A., Wong, J.S.S.: Adsorption of organic friction modifier additives. Langmuir 36, 1147-1155 (2020). https://doi.org/10.1021/acs.langmuir.9b03668

35. Van Ravensteijn, B.G.P., Bou Zerdan, R., Seo, D., Cadirov, N., Watanabe, T., Gerbec, J.A., Hawker, C.J., Israelachvili, J.N., Helgeson, M.E.: Triple function lubricant additives based on organicinorganic hybrid star polymers: friction reduction, wear protection, and viscosity modification. ACS Appl. Mater. Interfaces 11, 1363-1375 (2019). https://doi.org/10.1021/acsami.8b16849

36. Murdoch, T.J., Pashkovski, E., Patterson, R., Carpick, R.W., Lee, D.: Sticky but slick: reducing friction using associative and nonassociative polymer lubricant additives. ACS Appl. Polym. Mater. (2020). https://doi.org/10.1021/acsapm.0c00687

37. Dardin, A., Mueller, M., Eisenberg, B.: Lubricating oil composition with good frictional properties, US Patent No. 8,288,327 B2 (2012)

38. Sauerbrey, G.: Verwendung von Schwingquarzen zur Wägung dünner Schichten und zur Mikrowägung. Z. Phys. 155, 206-222 (1959). https://doi.org/10.1007/BF01337937

39. Ernesto, A., Mazuyer, D., Cayer-Barrioz, J.: The combined role of soot aggregation and surface effect on the friction of a lubricated 
contact. Tribol. Lett. 55, 329-341 (2014). https://doi.org/10.1007/ s11249-014-0365-5

40. Meng, X.Y., Sun, Y.K., Cao, F.L., Wu, J.T., Vesovic, V.: Reference correlation of the viscosity of $\mathrm{n}$-hexadecane from the triple point to $673 \mathrm{~K}$ and up to $425 \mathrm{MPa}$. J. Phys. Chem. Ref. Data. 47, 33102 (2018). https://doi.org/10.1063/1.5039595

41. Roelands, C.J.A.: Correlational Aspects of the Viscosity-Temperature-Pressure Relationship of Lubricating Oils. Ph.D. thesis, Technische Hogeschool te Delft (1966)

42. Chevalier, F.: Modélisation des Conditions d'Alimentation dans les Contacts Elastohydrodynamiques Ponctuels. PhD thesis, INSA Lyon, France (1996) (in French)
43. Crespo, A., Mazuyer, D., Morgado, N., Tonck, A., Georges, J.M., Cayer-Barrioz, J.: Methodology to characterize rheology, surface forces and friction of confined liquids at the molecular scale using the ATLAS apparatus. Tribol. Lett. (2017). https://doi.org/10. 1007/s11249-017-0921-x

Publisher's Note Springer Nature remains neutral with regard to jurisdictional claims in published maps and institutional affiliations.

\section{Authors and Affiliations}

\section{Tobias A. Gmür ${ }^{1}$. Joydeb Mandal ${ }^{1,2}$. Juliette Cayer-Barrioz ${ }^{3} \cdot$ Nicholas D. Spencer $^{1}$ (B)}

Nicholas D. Spencer nspencer@ethz.ch

1 Laboratory for Surface Science and Technology, Department of Materials, ETH Zürich, Vladimir-Prelog-Weg 5, 8093 Zurich, Switzerland
2 School of Chemistry, IISER Thiruvananthapuram, Maruthamala PO, Vithura, Thiruvananthapuram, Kerala 695551, India

3 Laboratoire de Tribologie et Dynamique des Systèmes, CNRS UMR 5513, Ecole Centrale de Lyon, 36 Avenue Guy de Collongue, 69134 Ecully Cedex, France 